\title{
Analyses of Insecticide Resistance Genes in Aedes aegypti and Aedes albopictus Mosquito Populations from Cameroon
}

\author{
Borel Djiappi-Tchamen ${ }^{1,2, *}$, Mariette Stella Nana-Ndjangwo ${ }^{2,3}$, Konstantinos Mavridis ${ }^{4}{ }^{\oplus}$, Abdou Talipouo ${ }^{2,3}$, \\ Elysée Nchoutpouen ${ }^{2}$, Idene Makoudjou ${ }^{2,3}$, Roland Bamou ${ }^{1,2}{ }^{10}$, Audrey Marie Paul Mayi ${ }^{1}$, \\ Parfait Awono-Ambene ${ }^{2}$, Timoléon Tchuinkam ${ }^{1}$, John Vontas ${ }^{4,5}$ and Christophe Antonio-Nkondjio ${ }^{2,6, *}$
}

1 Vector Borne Diseases Laboratory of the Applied Biology and Ecology Research Unit (VBID-URBEA), Department of Animal Biology, Faculty of Science, University of Dschang, P.O. Box 067 Dschang, Cameroon; bamou2011@gmail.com (R.B.); mayimariepaulaudrey@yahoo.com (A.M.P.M.); timotchuinkam@yahoo.fr (T.T.)

2 Institut de Recherche de Yaoundé (IRY), Organisation de Coordination pour la lutte Contre les Endémies en Afrique Centrale (OCEAC), P.O. Box 288 Yaoundé, Cameroon; stellanana123@gmail.com (M.S.N.-N.); atalipouo@gmail.com (A.T.); enchoutpouen2002@yahoo.fr (E.N.); idenemakoudjou@mail.com (I.M.); hpaawono@yahoo.fr (P.A.-A.)

3 Department of Animal Physiology and Biology, Faculty of Science, University of Yaoundé I, P.O. Box 337 Yaoundé, Cameroon

4 Institute of Molecular Biology and Biotechnology, Foundation for Research and Technology-Hellas, 70013 Heraklion, Greece; mavridiskos@gmail.com (K.M.); vontas@imbb.forth.gr (J.V.)

Citation: Djiappi-Tchamen, B.; Nana-Ndjangwo, M.S.; Mavridis, K.; Talipouo, A.; Nchoutpouen, E.; Makoudjou, I.; Bamou, R.; Mayi, A.M.P.; Awono-Ambene, P.;

Tchuinkam, T.; et al. Analyses of Insecticide Resistance Genes in Aedes aegypti and Aedes albopictus Mosquito Populations from Cameroon. Genes 2021, 12, 828. https://doi.org/ $10.3390 /$ genes 12060828

Academic Editor: Pedro Lorite

Received: 16 March 2021

Accepted: 5 May 2021

Published: 28 May 2021

Publisher's Note: MDPI stays neutral with regard to jurisdictional claims in published maps and institutional affiliations.

Copyright: (c) 2021 by the authors. Licensee MDPI, Basel, Switzerland. This article is an open access article distributed under the terms and conditions of the Creative Commons Attribution (CC BY) license (https:/ / creativecommons.org/licenses/by/ $4.0 /)$.
5 Pesticide Science Laboratory, Department of Crop Science, Agricultural University of Athens, 11855 Athens, Greece

6 Department of Vector Biology, Liverpool School of Tropical medicine, Pembroke Place, Liverpool L3 5QA, UK

* Correspondence: borel_tchamen@yahoo.com (B.D.-T.); antonio_nk@yahoo.fr (C.A.-N.)

Abstract: The emergence of insecticide resistance in Aedes mosquitoes could pose major challenges for arboviral-borne disease control. In this paper, insecticide susceptibility level and resistance mechanisms were assessed in Aedes aegypti (Linnaeus, 1762) and Aedes albopictus (Skuse, 1894) from urban settings of Cameroon. The F1 progeny of Aedes aegypti and Aedes albopictus collected in Douala, Yaoundé and Dschang from August to December 2020 was tested using WHO tube assays with four insecticides: deltamethrin $0.05 \%$, permethrin $0.75 \%$, DDT $4 \%$ and bendiocarb $0.1 \%$. TaqMan, qPCR and RT-qPCR assays were used to detect kdr mutations and the expression profiles of eight detoxification genes. Aedes aegypti mosquitoes from Douala were found to be resistant to DDT, permethrin and deltamethrin. Three kdr mutations, F1534C, V1016G and V1016I were detected in Aedes aegypti populations from Douala and Dschang. The kdr allele F1534C was predominant (90\%) in Aedes aegypti and was detected for the first time in Aedes albopictus (2.08\%). P450s genes, Cyp9J28 (2.23-7.03 folds), Cyp9M6 (1.49-2.59 folds), Cyp9J32 (1.29-3.75 folds) and GSTD4 (1.34-55.3 folds) were found overexpressed in the Douala and Yaoundé Aedes aegypti populations. The emergence of insecticide resistance in Aedes aegypti and Aedes albopictus calls for alternative strategies towards the control and prevention of arboviral vector-borne diseases in Cameroon.

Keywords: Aedes aegypti; Aedes albopictus; insecticide resistance diagnostics; arbovirus; mechanisms; urban settings; Cameroon

\section{Introduction}

Mosquitoes of the Aedes genus particularly Aedes aegypti and Aedes albopictus are major vectors of five important arboviral diseases worldwide (dengue, chikungunya, rift valley fever, yellow fever virus and zika) [1,2]. Aedes aegypti originates from Africa, whereas Aedes albopictus originates from South East Asia [3,4]. These two species, which now overlap in most of their distribution range appear to be well adapted to the urban environment [5,6]. In recent decades, arboviral diseases such as dengue and chikungunya have been increasingly reported across sub-Saharan Africa with important outbreaks 
reported in major urban settings [7-15]. These changes in the epidemiology of arboviral diseases could be closely linked to the co-occurrence of these two competent vector species in most epidemiological settings [16-20]. In Cameroon, frequent occurrence of arboviruses outbreaks or sporadic cases of yellow fever, dengue, chikungunya and Zika were reported in the early 2000s, a few years after the introduction of Aedes albopictus in the country [21-27]. Due to the lack of effective drugs and vaccines against most of these arbovirus diseases, vector management is the main strategy for reducing transmission and preventing outbreaks [28,29]. Approaches for controlling Aedes spp vector populations include active community participation in vector control interventions, health education programs, reduction of breeding sites, environmental management, improvements of water supplies and storage, solid waste management, modification of human-made larval habitats and insecticide use [30-34]. Insecticide-based intervention is the main strategy routinely used to control mosquito populations [35]. Despite the increasing nuisance due to Aedes mosquitoes bites, there have been so far limited control efforts targeting specifically Aedes mosquitoes populations. Most vector control efforts are directed against malaria vectors with the massive deployment of insecticide-treated nets [36]. It is likely that the scaling up of insecticide-treated nets alongside the intensive use of insecticides in agriculture could be affecting non-malaria vector species [37] and could lead to the development of resistance within Aedes mosquito populations [20,38,39]. Mosquitoes may display one or more resistance mechanisms, making them less susceptible to insecticides [40]. These include behavioral changes [41,42], alterations of the cuticle to reduce insecticide penetration [43-46], target site resistance [41,42] and increased detoxification metabolism involving genes such as cytochrome P450 monooxygenases (P450s), carboxylesterases (COEs) and glutathione S-transferases (GSTs) [47-52].

Several cytochrome P450s (CYPs), more often members of the CYP6 and CYP9 families, have been associated with resistance in Aedes vectors [53-55]. The AaegCYP9J28 and the AaegCYP6BB2 are detected more often and consistently across studies in Ae. (Aedes) aegypti. AaegCYP9J32 has been associated with pyreroid resistance in Thailand, Mexico and Vietnam; AaegCYP9J24 and AaegCYP9J26 in Latin America and Singapore; and AaegCYP9M6 and AaegCYP4D24 in Asia and Puerto Rico, respectively [55]. The AalCYP6P12 has been associated with pyrethroid resistance in Ae. albopictus populations from Malaysia [56].

Mutations in the voltage-gated sodium channel (VGSC) are common in Ae. aegypti, with 10 mutations at eight codon positions in VGSC domains II-IV identified to date [53]. Their geographical distribution and frequency vary: the most widespread mutation in both Ae. aegypti aegypti and Ae. aegypti formosus is the 1534C across continents. The V1016I and V1016G mutations have been also found in Asia, in the Americas and in Africa [53].

Previous studies examining general resistance status of the two main vectors Ae. aegypti and Ae. albopictus in different ecological settings across Cameroon indicated that Aedes albopictus and Aedes aegypti were both resistant to $0.05 \%$ deltamethrin, $0.01 \%$ bendiocarb and $4 \%$ DDT (dichlorodiphenyltrichloroethane). Furthermore, they were recorded to be partly susceptible to $0.75 \%$ permethrin and fully susceptible to malathion $5 \%[38,39,57,58]$. Although pre-exposure of mosquitoes to the synergist PBO (piperonil butoxide) or DEM (diethyl maleate) increased mosquito susceptibility status to permethrin, deltamethrin and DDT, it is not clear which detoxification genes are involved in insecticide metabolism as well as additional mechanisms involved in Aedes resistance to insecticides.

In the present study, the insecticide resistance profile of adult Ae. aegypti and Ae. albopictus from three different urban settings was determined by WHO bioassays, and subsequently, the underlying resistance mechanisms were investigated using molecular tools, to detect genes and mutations associated with insecticide resistance in these vector populations.

We tested the hypothesis that Aedes populations across Cameroon could display a similar resistance profile ( $\%$ mortality) and similar resistance gene frequencies. 


\section{Materials and Methods}

\subsection{Study Sites}

The study was carried out in three cities of Cameroon (Figure 1), namely: Yaoundé (equatorial forest region), Douala (coastal region) and Dschang (highland region) (Table 1). These cities are situated at different altitudes.

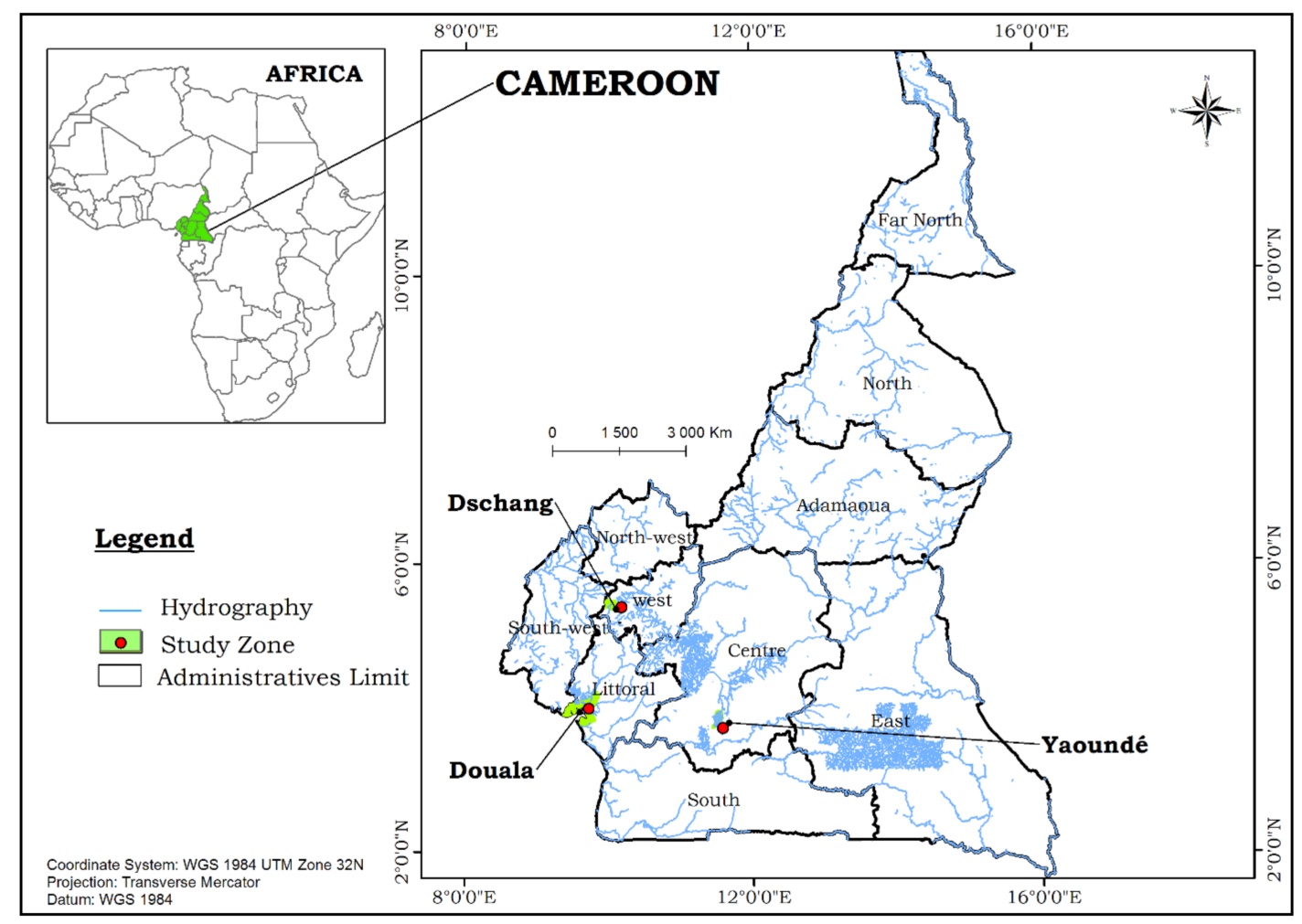

Figure 1. Localization of the study sites in Cameroon.

Table 1. Characteristics of the three study sites.

\begin{tabular}{cccc}
\hline & Yaoundé & Douala & Dschang \\
\hline Altitude above sea level & $726 \mathrm{~m}$ & $1 \mathrm{~m}$ & $1500 \mathrm{~m}$ \\
\hline Population size & $2,765,568$ & $2,768,436$ & 301,385 \\
\hline Surface area & $180 \mathrm{~km}^{2}$ & $210 \mathrm{~km}^{2}$ & $225 \mathrm{~km}^{2}$ \\
\hline Landscape & $\begin{array}{c}\text { Congo Guinean } \\
\text { equatorial forest }\end{array}$ & Coastal area & Highland area \\
\hline Annual rainfall & $1700 \mathrm{~mm}$ & 4000 to $5000 \mathrm{~mm}$ & $1364 \mathrm{~mm}$ \\
\hline
\end{tabular}

Mosquito sampling in Yaoundé was conducted in the districts of Mvan, Obili and Simbock. In Douala collections were done in Bonaberi, Yassa and Village while in Dschang, mosquitoes were collected in Foréké, Tsinbing and Paidground.

\subsection{Collection of Mosquito Larvae, Rearing and Processing}

Immature stages of Aedes mosquitoes were collected in each city from artificial breeding sites such as used tires around houses and garages, discarded plastics containers and metallic containers from August to December 2020. The collected immature stages were pooled (according to cities) and reared to adult stage under standard laboratory conditions (27-28 ${ }^{\circ} \mathrm{C}$ temperature; $70-80 \%$ hygrometry). Those collected in Dschang were reared at the VBID-URBEA of the University of Dschang. Samples from Douala and Yaoundé were reared in the insectary of the Malaria Research Laboratory of OCEAC. Pupae were 
collected daily and transferred in cages for adult emergence. Adult mosquitoes were provided continuous access to $10 \%$ glucose solution. Morphological identification of Aedes mosquitoes from each study site was done under a stereomicroscope with the keys of jupp (1996) [59]. A first subset of 50-60 unexposed non-blood fed mosquito females aged 3-5 days were preserved in RNA later (SIGMA Aldrich, Saint Louis, MO, USA) for characterization of molecular mechanisms of insecticide resistance. The remaining mosquito species were fed on chicken blood for egg-laying, and insecticide susceptibility bioassays were conducted with females of the F1 generation. After bioassays, survivors against all insecticides were preserved in 70\% ethanol and sent to IMBB-FORTH (Greece). Mosquitoes that survived exposure to insecticides were used for kdr genotyping analysis and species identification (PCR).

\subsection{Insecticide Susceptibility Tests}

Bioassays were performed following the WHO guidelines [60] with four insecticide classes. For each mosquito population, four replicates of $20 \mathrm{~F} 1$ females each were exposed to insecticides impregnated papers. Aedes mosquitoes were exposed to $0.05 \%$ deltamethrin (only for Aedes aegypti population from Douala), 0.75\% permethrin, 4\% DDT and $0.1 \%$ bendiocarb; most of the impregnated papers are prepared by diluting the insecticide in silicone oil (solvent). Aedes species were exposed to these discriminating insecticide doses instead of their normal discriminating dose because they share similar habitats with Anopheles gambiae and Culex quinquefasciatus who happen to be highly resistant to insecticides, and we wanted to assess whether Aedes populations have similar resistance profile. Previous studies in Cameroon reported Aedes aegypti populations to be resistant to their normal discriminating doses [39,58]. For each bioassay, two replicates of 20 female mosquitoes unexposed to any insecticide were used as an internal control. A susceptible strain of Ae. aegypti and Ae. albopictus mosquitoes from Cameroon were used to validate the efficacy of the impregnated papers. After $60 \mathrm{~min}$ of exposure, mosquitoes were transferred into holding tubes (12 cm in height; $4.2 \mathrm{~cm}$ diameter) and supplied with $10 \%$ glucose. The mortality rate was recorded $24 \mathrm{~h}$ post-insecticide exposure, mosquitoes that survived exposure to insecticides were used for kdr genotyping analysis and species identification through PCR.

\subsection{Total Nucleic Acids (NAs) Extraction from Mosquito Pools and gDNA Extraction from Individual Mosquitoes}

Total NAs were extracted from pooled mosquito specimens ( $\mathrm{N}=10$ mosquitoes per pool) using the MagSi magnetic beads extraction kit (Magnamedics) as previously described [61]. For gene expression analysis (RNA) mosquitoes unexposed to insecticides, non-blood-fed females, aged 3-5 days, were used. For genotyping (DNA), mosquitoes that had previously survived exposure to insecticides were used. The quantity of total NA was assessed spectrophotometrically (Nanodrop). The quality of RNA was assessed by $1.0 \%$ $w / v$ agarose gel electrophoresis (Supplementary Figure S1). Genomic DNA (gDNA) from individual mosquitoes was extracted with the DNAzol (MRC, Inc., Saint Louis, MO, USA) protocol according to the manufacturer's instructions.

\subsection{Genotyping of Mosquito Sample and Multiplex RT-qPCR for Gene Expression Analysis}

Species identification at the molecular level was performed using the TaqMan assay of Kothera et al. [62]. Previously developed and validated triplex TaqMan (RT-qPCR) assays (Supplementary Table S1) were used for the quantification of 07 detoxification genes' expression (Cyp6BB2, Cyp9J26, GSTD4, CCEae3a, Cyp9J28, Cyp9M6 and Cyp9J32) including RPL8 for normalization purposes in each assay as previously described. Primers were designed in the exon-exon junctions for all genes, thus eliminating the need for a DNase digestion step [63]. TaqMan assays were also used for detecting kdr mutations F1534C, V1016G, V1016I and S989P in gDNA from Ae. aegypti and F1534C in gDNA from Ae. albopictus mosquitoes (Supplementary Table S2) as previously described [63]. Wild-type, mutant and heterozygous gBlocks ${ }^{\mathrm{TM}}$ Gene Fragments control sequences (IDT, Coralville, 
IA, USA) for each mutation (Supplementary Table S2) were included in each run to better facilitate the genotyping call [63]. Reactions were performed in the Viia7 Real-Time PCR system (Applied Biosystems, Foster City, CA, USA) using a one-step RT-PCR mastermix supplied by FTD (Fast-track diagnostics, Esch-sur-Alzette, Luxembourg) in a total reaction volume of $10 \mu \mathrm{L}$. The thermal cycle parameters were: $50{ }^{\circ} \mathrm{C}$ for $15 \mathrm{~min}, 95^{\circ} \mathrm{C}$ for $3 \mathrm{~min}$, and 40 cycles of $95^{\circ} \mathrm{C}$ for $3 \mathrm{~s}$ and $60^{\circ} \mathrm{C}$ for $30 \mathrm{~s}$. Samples were amplified in duplicates and each run always included a non-template control.

\subsection{Statistical Analysis}

For adult insecticide bioassays, the status of mosquitoes was defined by mortality rate: confirmed resistance if mortality $<90 \%$, possible resistance if mortality is between 90 and $98 \%$, and susceptible if mortality $>98 \%$ [60]. Calculation of fold-changes, $95 \%$ confidence intervals (CI) and statistical significance was performed according to the Pfaffl method [64]. More precisely gene expression analysis was performed using the REST@ 2009 (v2.0.13) [65] software that uses a Pair-Wise Fixed Reallocation Randomization Test to statistically analyze the gene expression data. Graphs were constructed with the SigmaPlot software (v12.0).

\section{Results}

\subsection{Insecticide Bioassays Results}

Adult bioassays revealed different susceptibility levels against DDT ranging from $68.75 \%$ to $100 \%$ in the three field populations of Ae. Aegypti and Ae. Albopictus. Ae. Albopictus populations were fully susceptible to permethrin and deltamethrin insecticides, while Ae. aegypti from Douala displayed high resistance to both deltamethrin $0.05 \%$ and permethrin $0.75 \%$. Both species were fully susceptible to bendiocarb (Figure 2 ) in all study sites. There was no significant difference when comparing the mortality rate of Aedes aegypti populations between sites $(p>0.05)$. A significant difference in the mortality rate of Aedes albopictus populations was recorded when comparing Yaoundé to Dschang population to DDT $4 \%(p<0.001)$ and for Bendiocard between Yaoundé and Douala populations $(p=0.03)$.

\subsection{Species Identification}

A total of 184 specimens were genotyped to confirm the morphological identification of Aedes species in each locality. A subsample of 72 Aedes albopictus and 72 Aedes aegypti identified morphologically were further processed by PCR and all turned to confirm morphological identifications.

\subsection{Screening of Target Site Mutations (kdr F1534C, V1016G, V1016I and S989P)}

The distribution of different mutations associated with insecticide resistance was assessed. In Ae. aegypti, a total of three-point mutations were detected (Table 2), namely F1534C, V1016G and V1016I. Among these, the mutation F1534C was highly predominant $(>60 \%$ ) and was detected in Douala and Dschang (Table 3). The V1016G kdr allele was detected only in the population of Douala. Furthermore, the V1016I allele was found with a frequency ranging from 26.7 to $60 \%$ in Ae. aegypti mosquitoes from Douala and Dschang, respectively. No mosquito was found with the S989P mutation and no mutation was found in both Aedes aegypti and Aedes albopictus in Yaoundé. 

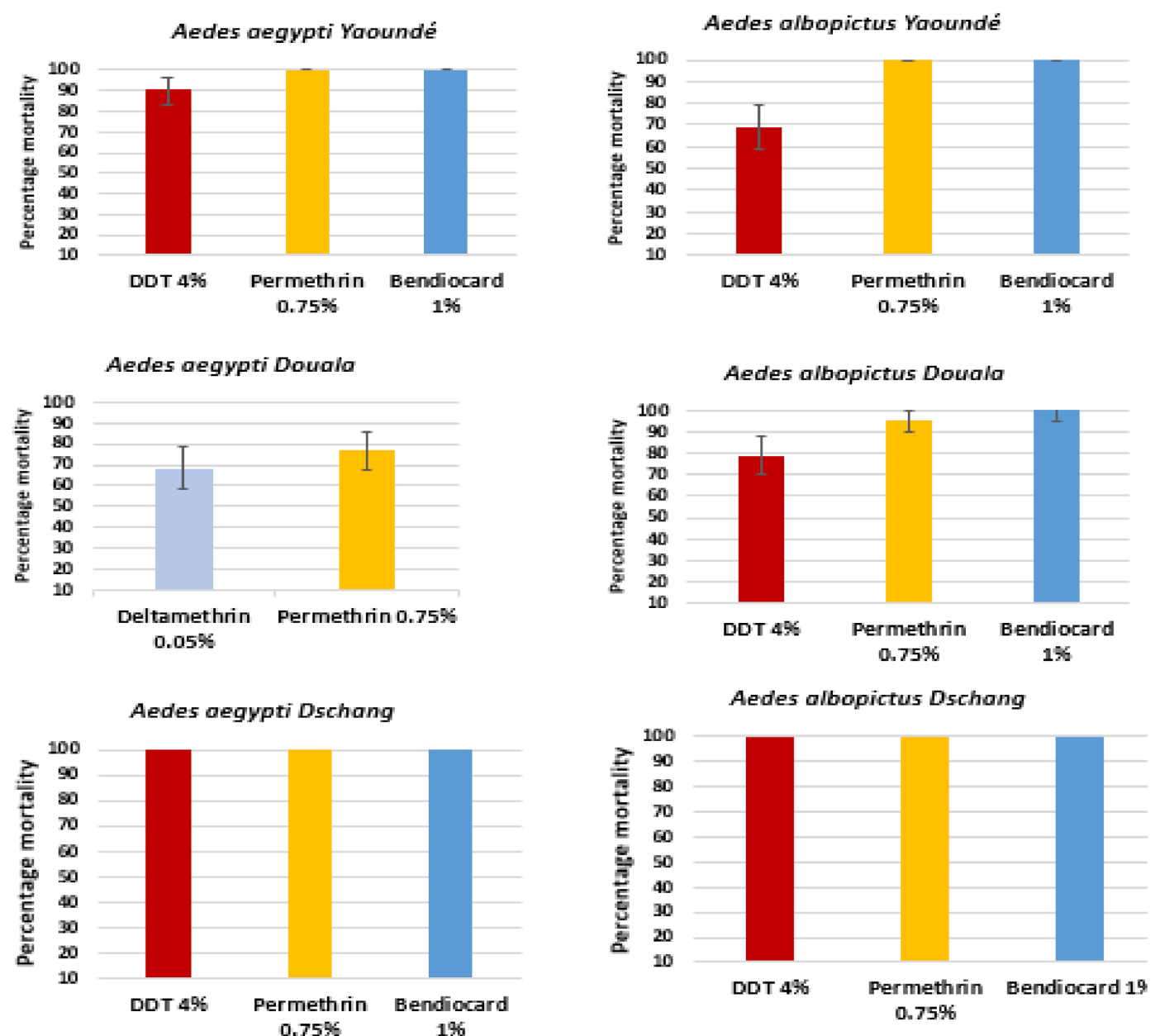

Figure 2. Susceptibilities profiles of Aedes aegypti and Aedes albopictus in Yaoundé, Douala and Dschang. Error bars represent $95 \%$ confidence intervals.

Table 2. Frequency of kdr resistance alleles in different populations of Ae. aegypti mosquitoes.

\begin{tabular}{|c|c|c|c|c|c|}
\hline \multirow{3}{*}{ Population } & \multirow{3}{*}{$\begin{array}{l}\text { Sample Size } \\
\text { (Alleles) }\end{array}$} & \multicolumn{4}{|c|}{$\begin{array}{l}\text { Resistant Mutation Allelic Frequencies } \\
\text { (Heterozygous/Homozygous Mosquitoes) }\end{array}$} \\
\hline & & \multicolumn{4}{|c|}{ Pyrethroids/DDT } \\
\hline & & $\%$ F1534C & $\%$ V1016G & $\%$ V1016I & \% S989P \\
\hline Yaoundé & 64 & $0.0(0 / 0)$ & $0.0(0 / 0)$ & $0.0(0 / 0)$ & $0.0(0 / 0)$ \\
\hline Douala & 60 & $90.0(6 / 24)$ & $1.7(1 / 0)$ & $26.7(14 / 1)$ & $0.0(0 / 0)$ \\
\hline Dschang & 20 & $60.0(2 / 2)$ & $0.0(0 / 0)$ & $60.0(2 / 2)$ & $0.0(0 / 0)$ \\
\hline Cameroon & & & & & \\
\hline $\begin{array}{c}\text { Ae. aegypti } \\
\text { susceptible strain }\end{array}$ & 40 & $0.0(0 / 0)$ & $0.0(0 / 0)$ & $0.0(0 / 0)$ & $0.0(0 / 0)$ \\
\hline
\end{tabular}
very low frequency $(2.08 \%)$ (Table 3$)$ 
Table 3. Incidence of resistance alleles in different populations of Ae. albopictus mosquitoes, assayed by TaqMan qPCR.

\begin{tabular}{ccc}
\hline \multirow{2}{*}{$\begin{array}{c}\text { Population } \\
\text { Sample Size (Alleles) }\end{array}$} & $\begin{array}{c}\text { Resistant Mutation Allelic Frequencies } \\
\text { (Heterozygous/Homozygous Mosquitoes) }\end{array}$ \\
& & Pyrethroids/DDT \\
\cline { 2 - 2 } Yaoundé & 48 & $0.0(0 / 0)$ \\
Douala & 48 & $2.08(1 / 0)$ \\
Dschang & 48 & $0.0(0 / 0)$ \\
Cameroon Ae. & 40 & $0.0(0 / 0)$ \\
albopictus susceptible & & \\
strain & 40 &
\end{tabular}

$(\mathrm{a} / \mathrm{b})=$ number of heterozygous/homozygous mosquitoes.

\subsection{Analysis of Detoxification Genes Expression Profile}

Quantitative RT-qPCR analyses revealed the overexpression profile of seven different detoxification genes in resistant Aedes aegypti from the three study sites namely, Cyp6BB2, Cyp9J26, GSTD4, CCEae3a, Cyp9J28, Cyp9M6 and Cyp9J32 (Table 4). High overexpression ratios were recorded for three P450 cytochrome genes, namely Cyp9J28 (2.84-7.55), Cyp9M6 (1.19-2.13) and Cyp9J32 (2.82-4.72) in Yaoundé samples. In Douala samples, overexpressed detoxification genes included GSTD4 (1.34-55.3), Cyp9J28 (2.23-7.03), Cyp9M6 (1.49-2.59) and Cyp9J32 (1.29-3.75). In Dschang populations, these seven detoxification genes were also found, but no overexpression was recorded.

Table 4. Expression analysis of the detoxification genes analyzed in the three resistant Aedes aegypti mosquito populations compared to the susceptible mosquito strain.

\begin{tabular}{|c|c|c|c|c|c|c|c|}
\hline \multirow[t]{2}{*}{ Populations } & \multicolumn{7}{|c|}{$\begin{array}{l}\text { Detoxification Gene Fold Changes } \\
(95 \% \mathrm{CI}), p \text { Value }\end{array}$} \\
\hline & Сур6ВВ2 & Сур9J26 & GSTD4 & ССЕаеЗ & Сур9J28 & Сур9М6 & Сур9J32 \\
\hline \multirow{4}{*}{ Yaoundé } & 1.09 & 1.91 & 10.1 & 1.59 & $4.67^{*}$ & $1.56^{*}$ & $3.58 *$ \\
\hline & $(0.773-1.48) p$ & $(0.936-3.88)$ & $(0.630-39.0)$ & $(0.961-2.61)$ & $(2.84-7.55)$ & $(1.19-2.13)$ & $(2.82-4.72)$ \\
\hline & $=0.509$ & $p=0.075$ & $p=0.101$ & $p=0.071$ & $p<0.001$ & $p<0.001$ & $p=0.032$ \\
\hline & 0.556 & 1.621 & 9.34 * & 0.503 & $3.57^{*}$ & $1.88 *$ & $1.98 *$ \\
\hline \multirow[t]{2}{*}{ Douala } & $(0.364-0.853)$ & $(0.697-3.48)$ & $(1.34-55.3)$ & $(0.251-1.01)$ & $(2.23-7.03)$ & $(1.49-2.59)$ & $(1.29-3.75)$ \\
\hline & $p<0.001$ & $p=0.298$ & $p=0.030$ & $p=0.052$ & $p<0.001$ & $p<0.001$ & $p<0.001$ \\
\hline \multirow{3}{*}{ Dschang } & 0.335 & 0.368 & 12.1 & 1.04 & 0.762 & 0.851 & 1.37 \\
\hline & $(0.122-0.890)$ & $(0.235-0.649)$ & $(0.840-40)$ & (0.900-1.183) & $(0.251-2.27)$ & $(0.655-1.14)$ & $(0.518-3.74)$ \\
\hline & $p<0.001$ & $p<0.001$ & $p=0.198$ & $p=0.507$ & $p=0.695$ & $p=0.285$ & $p=0.714$ \\
\hline
\end{tabular}

$*$ indicate statistically significant overexpression $(p<0.05) ; 95 \%$ CIs are given in parentheses.

\section{Discussion}

Aedes aegypti and Aedes albopictus are recognized as the main vectors of arboviruses in Cameroon [20,38,66,67]. Knowledge of their susceptibility and insecticide resistance profile is important for the implementation of successful vector control programs across the country. In the present study, the resistance profile to insecticides of both Aedes aegypti and Aedes albopictus from three urban settings in Cameroon was determined, and subsequently, genes and mechanisms conferring insecticide resistance in these vector populations were investigated. Ae. albopictus populations from the three sites were fully susceptible to permethrin and bendiocarb; however, a high resistance profile was detected against DDT in both Douala and Yaoundé. These results are in accordance with recent studies in the city of Douala and Yaoundé $[39,58]$. The rapid expansion of insecticide resistance in this species could result from domestic pollution or organic pollutants since Aedes albopictus is largely prevalent in water containers, spare tires, and discarded containers, which happen to be largely prevalent in agricultural cultivated sites [68]. It is also possible that this species sus- 
ceptibility could have been affected by the increased use of insecticide repellents or through fumigation which is increasingly practiced in urban settings. Migration and founder effect could also be possible factors however these deserve further investigations $[69,70]$.

Aedes aegypti, recorded alongside Aedes albopictus, was found much more resistant to pyrethroids in Douala. Similar observations were made previously [58]. The following supports high selection pressure by insecticides in Aedes aegypti compared to Aedes albopictus. It is likely that these species display different feeding and resting behavior, which could explain varying exposure to insecticides. Indeed, Aedes aegypti and Ae. albopictus have frequently been reported indoors. This particular behavior could have exposed them to the use of indoor base interventions such as insecticide sprays, aerosols, or treated nets. The high use of insecticides in households to prevent nuisance has been documented in different urban settings [71-73]. The high resistance profile in Ae. aegypti compared to Ae. albopictus has been reported in different epidemiological settings across West and Central Africa $[17,74]$. Very high resistance level to DDT was recorded in the different study sites even though this compound is no more used for vector control. It is possible that Aedes populations are still exposed to DDT through their use in agriculture or through long-term environmental persistence of organochlorine [73]. Adult mosquitoes in the three sites displayed high susceptibility to deltamethrin, particularly Ae. Albopictus, and could be explained by the fact that we used previous deltamethrin discriminating concentration of $0.05 \%$, whereas the new tentative discriminating dose recommended for Aedes is now $0.03 \%$ [75].

Three kdr mutations F1534C, V1016G and V1016I out of the eleven previously detected in Ae. aegypti populations $[53,76]$ were recorded in the present study. Some of these alleles (F1534C) were detected at an extremely high frequency close to fixation in Douala (90.0\%) and at medium frequency $(60.0 \%)$ in Dschang. The F1534C mutation was detected at a very high frequency (90\%) compared to previous reports in the city of Douala (frequency $33.3 \%$ ) [57] and suggests an increased expansion of this gene in Cameroon, which is the most represented across Africa [53]. Studies in Burkina Faso and Angola identified this allele close to fixation [53,77,78]; in Ghana, it was recorded with a frequency of 35.0\% [79]. Two novel mutations V1016G and V1016I were also recorded. V1016I mutation was detected in Douala and Dschang. V1016G was also detected, albeit at a very low frequency in Douala (1.7\%). The V1016I allele has previously been detected in Burkina Faso [77,78] and Ghana [80]. V1016G is largely distributed in Asia and V1016I in the Americas [53]. These genes could have emerged spontaneously or appeared through recent migration events in Africa [53]. The V1016G allele was reported to confer insensitivity to permethrin and deltamethrin, whereas the F1534C mutation was reported to confer resistance to permethrin $[73,81]$. The low resistance level to deltamethrin recorded during the present study could have resulted from the low frequency of V1016G allele in our samples and is consistent with previous findings elsewhere [73]. The three mutations S989P, V1016G and F1534C when occurring simultaneously in an individual were reported to confer a very high level of pyrethroid resistance [82,83]. It seems like resistance in Aedes mosquitoes is still not largely expanded across Central Africa, since Ae. aegypti mosquito populations from Congo [84] and Central African Republic [85] were reported to be free of these mutations.

Aedes albopictus mosquito population from Douala were found to carry the kdr F1354C mutation at a very low frequency (2.08\%). This is the first detection of F1534C allele in Ae. albopictus mosquitoes in Cameroon and in Africa [57]. Thus far, three mutations at codon 1534 (F to C, L and S) have been reported in Aedes albopictus. The variant F1534S has been demonstrated to be moderately associated with resistance to DDT and pyrethroids [86,87]. As compared to Aedes aegypti which has eleven mutations occurring at 08 codons in the voltage-gated sodium channel, mutations on this gene in Aedes albopictus are less important since only four mutations affecting 02 codons (1532 and 1534) have been detected [53].

The expression levels of seven major detoxification genes (Cyp6BB2, Cyp9J26, GSTD4, CСЕae3a, Cyp9J28, Cyp9M6, Cyp9J32) involved in insecticide resistance in Ae. aegypti were analyzed with recently developed multiplex TaqMan RT-qPCR assays. The P450s 
genes CYP9J28, CYP9M6 and CYP9J32 were significantly overexpressed in Yaoundé and Douala samples compared to the susceptible laboratory strain. CYP9J28 and CYP9J32 were recorded overexpressed in pyrethroid-resistant Aedes aegypti populations from Mexico, Peru and Cuba $[53,88]$. P450 detoxification genes including CYP9J10, CYP6BB2, CYP9J26 and CYP9J28 have been proven to metabolize pyrethroids [52,89] or to confer pyrethroid resistance when expressed transgenically in Drosophila [90]. From the review of Moyes et al. [53], it appeared that CYP6 and CYP9 genes were also the most commonly duplicated P450s genes in Ae. aegypti, suggesting that a copy number of variation may play an important role in differential expression phenotypes, although further studies are needed to confirm this hypothesis [53]. GSTD4 was found significantly overexpressed in the Douala Aedes population. GSTs alongside P450 genes have been reported to be involved in pyrethroid resistance in Aedes aegypti populations [19]. The present study is one of the few on Ae. aegypti in Africa, supporting at least partial involvement of metabolic base mechanisms in mosquito resistance to insecticides.

\section{Conclusions}

Target sites mutations and/or metabolic-based mechanisms were found to be associated with insecticide resistance in Aedes aegypti and Aedes albopictus in Cameroon. Although resistance is still not largely expanded in Aedes populations and does not affect all insecticide classes, the situation calls for immediate action in order to improve the control of Aedes populations. With the increasing number of arbovirus outbreaks in Cameroon and neighboring countries, it is becoming urgent that further strategies be implemented to improve vector control and prevent the spread of arboviral diseases.

Supplementary Materials: The following are available online at https:/ /www.mdpi.com/article/10 .3390/genes12060828/s1, Figure S1: Agarose gel electrophoresis for total RNA extracted (presented for randomly selected samples); Table S1: Oligos used in the multiplex RT-qPCR assays for gene expression analysis and their analytical properties; Table S2: Primers, probes and control sequences used for TaqMan kdr genotyping

Author Contributions: B.D.-T. and C.A.-N. conceptualized and designed the study; B.D.-T., E.N., M.S.N.-N., I.M., A.T., A.M.P.M. and R.B. performed the field experiments; B.D.-T., M.S.N.-N., K.M., I.M., E.N., A.T., A.M.P.M. and R.B. performed laboratory experiments. B.D.-T. and K.M. performed the statistical analysis. K.M., M.S.N.-N., T.T., P.A.-A. and J.V. critically reviewed and amended the manuscript. B.D.-T. and C.A.-N. interpreted and analyzed data and wrote the manuscript with input from all authors. All authors have read and agreed to the published version of the manuscript.

Funding: This study was partly sponsored by a Wellcome Trust Senior Fellowship in Public Health and Tropical Medicine (202687/Z/16/Z) to CAN. Part of this research received funding from the European Union's Horizon 2020 research and innovation program under grant agreement No. 731,060 (INFRAVEC2) to B.D.-T. and from the MTN-KFW program awarded to N-DSM.

Institutional Review Board Statement: The study was conducted according to the guidelines of the Declaration of Helsinki, and approved by the Cameroon national Ethics Committee for research on human health, Ethical Clearance $\mathrm{N}^{0}$ 2018/06/1039/CE/CNERSH/SP REF N ${ }^{0}$ D30172/LMINSANTE/SG/DROS/TMC of the 4 April 2017.

Informed Consent Statement: Not applicable.

Data Availability Statement: All the data from the study is available in the manuscript.

Acknowledgments: We are grateful to Kala Chouakeu Nelly Armanda, Djoufouna Joel, Nguangue Nasser, Ouaba José, Lontsi Demano Michel for their assistance during the fieldwork. We are thankful to all the garage owners for giving their consent during entomological survey and to Soulemane Mounchili for his contribution in designing the map of study sites.

Conflicts of Interest: The authors declare that they have no competing interests. 


\section{References}

1. Weetman, D.; Kamgang, B.; Badolo, A.; Moyes, C.L.; Shearer, F.M.; Coulibaly, M.; Pinto, J.; Lambrechts, L.; McCall, P.J. Aedes Mosquitoes and Aedes-Borne arboviruses in Africa: Current and future threats. Int. J. Environ. Res. Public Health 2018, 15, 220. [CrossRef] [PubMed]

2. Leta, S.; Beyene, T.J.; De Clercq, E.M.; Amenu, K.; Kraemer, M.U.G.; Revie, C.W. Global risk mapping for major diseases transmitted by Aedes aegypti and Aedes albopictus. Int. J. Infect. Dis. 2018, 67, 25-35. [CrossRef] [PubMed]

3. Cuervo-Parra, J.A.; Cortés, T.R.; Ramirez-Lepe, M. Mosquito-Borne diseases, pesticides used for mosquito control, and development of resistance to insecticides. Insectic. Resist. 2016, 7. [CrossRef]

4. Kraemer, M.U.G.; Sinka, M.E.; Duda, K.A.; Mylne, A.Q.N.; Shearer, F.M.; Barker, C.M.; Moore, C.G.; Carvalho, R.G.; Coelho, G.E.; Van Bortel, W.; et al. The global distribution of the arbovirus vectors Aedes aegypti and Aedes albopictus. Elife 2015, 4, e08347. [CrossRef] [PubMed]

5. Delatte, H.; Toty, C.; Boyer, S.; Bouetard, A.; Bastien, F.; Fontenille, D. Evidence of habitat structuring Aedes albopictus populations in Réunion Island. PLoS Negl. Trop. Dis. 2013, 7, e2111. [CrossRef] [PubMed]

6. Mayi, M.P.A.; Bamou, R.; Djiappi-Tchamen, B.; Fontaine, A.; Jeffries, C.L.; Walker, T.; Antonio-Nkondjio, C.; Cornel, A.J.; Tchuinkam, T. Habitat and seasonality affect mosquito community composition in the west region of Cameroon. Insects 2020, 11, 312. [CrossRef] [PubMed]

7. Lutomiah, J.; Barrera, R.; Makio, A.; Mutisya, J.; Koka, H.; Owaka, S.; Koskei, E.; Nyunja, A.; Eyase, F.; Coldren, R.; et al. Dengue outbreak in Mombasa City, Kenya, 2013-2014: Entomologic investigations. PLoS Negl. Trop. Dis. 2016, 10, e0004981. [CrossRef]

8. Ayolabi, C.I.; Olusola, B.A.; Ibemgbo, S.A.; Okonkwo, G.O. Detection of dengue viruses among febrile patients in Lagos, Nigeria and phylogenetics of circulating dengue serotypes in Africa. Infect. Genet. Evol. 2019, 75, 103947. [CrossRef]

9. Ouedraogo, S.; Degroote, S.; Barro, S.A.; Some, A.; Bonnet, E.; Ridde, V. Épidémies recurrentes de la dengue au burkina faso: Préférences communautaires pour une intervention de prevention de la maladie. Rev. d'Epidémiologie St. Publique 2019, 67, 375-382. [CrossRef]

10. Otu, A.; Udoh, U.; Ita, O.; Hicks, J.; Ukpeh, I.; Walley, J. Prevalence of Zika and Malaria in patients with fever in secondary healthcare facilities in South-Eastern Nigeria. Trop. Dr. 2020, 50, 22-30. [CrossRef]

11. Peyrefitte, C.N.; Rousset, D.; Pastorino, B.A.; Pouillot, R.; Bessaud, M.; Tock, F.; Mansaray, H.; Merle, O.L.; Pascual, A.M.; Paupy, C. Chikungunya virus, cameroon, 2006. Emerg. Infect. Dis. 2007, 13, 768-771. [CrossRef]

12. Vairo, F.; Haider, N.; Kock, R.; Ntoumi, F.; Ippolito, G.; Zumla, A. Chikungunya: Epidemiology, pathogenesis, clinical features, management, and prevention. Infect. Dis. Clin. 2019, 33, 1003-1025. [CrossRef]

13. Nkoghe, D.; Kassa, R.F.; Caron, M.; Grard, G.; Mombo, I.; Bikié, B.; Paupy, C.; Becquart, P.; Bisvigou, U.; Leroy, E.M. Clinical forms of chikungunya in Gabon, 2010. PLoS Negl. Trop. Dis. 2012, 6, e1517. [CrossRef]

14. Proesmans, S.; Katshongo, F.; Milambu, J.; Fungula, B.; Mavoko, H.M.; Ahuka-Mundeke, S.; da Luz, R.I.; Esbroeck, M.V.; Ariën, K.K.; Cnops, L.; et al. Dengue and chikungunya among outpatients with acute undifferentiated fever in Kinshasa, Democratic Republic of Congo: A cross-sectional study. PLoS Negl. Trop. Dis. 2019, 13, e0007047. [CrossRef]

15. Im, J.; Balasubramanian, R.; Ouedraogo, M.; Wandji Nana, L.R.; Mogeni, O.D.; Jeon, H.J.; van Pomeren, T.; Haselbeck, A.; Lim, J.K.; Prifti, K.; et al. The epidemiology of dengue outbreaks in 2016 and 2017 in Ouagadougou, Burkina Faso. Heliyon 2020, 6. [CrossRef]

16. Ndenga, B.A.; Mutuku, F.M.; Ngugi, H.; Mbakaya, J.O.; Aswani, P.; Musunzaji, P.S.; Vulule, J.; Mukoko, D.; Kitron, U.; LaBeaud, A.D. Characteristics of Aedes aegypti adult mosquitoes in rural and urban areas of western and coastal Kenya. PLoS ONE 2017, 12, e0189971. [CrossRef]

17. Namountougou, M.; Soma, D.; Balboné, M.; Kaboré, D.; Kientega, M.; Hien, A.; Coulibaly, A.; Ouattara, P.; Meda, B.; Drabo, S.; et al. Monitoring insecticide susceptibility in Aedes aegypti populations from the two biggest cities, Ouagadougou and Bobo-Dioulasso, in Burkina Faso: Implication of metabolic resistance. Trop. Med. Infect. Dis. 2020, 5, 84. [CrossRef]

18. Zahouli, J.B.Z.; Koudou, B.G.; Müller, P.; Malone, D.; Tano, Y.; Utzinger, J. Urbanization is a main driver for the larval ecology of Aedes Mosquitoes in arbovirus-endemic settings in South-Eastern Côte d'Ivoire. PLoS Negl. Trop. Dis. 2017, 11. [CrossRef]

19. Fagbohun, I.K.; Idowu, E.T.; Olakiigbe, A.K.; Oyeniyi, A.T.; Otubanjo, O.A.; Awolola, T.S. Metabolic resistance mechanism in Aedes aegypti from Lagos State, Nigeria. J. Basic Appl. Zool. 2020, 81, 59. [CrossRef]

20. Tedjou, A.N.; Kamgang, B.; Yougang, A.P.; Njiokou, F.; Wondji, C.S. Update on the geographical distribution and prevalence of Aedes aegypti and Aedes albopictus (Diptera: Culicidae), two major arbovirus vectors in Cameroon. PLoS Negl. Trop. Dis. 2019, 13, e0007137. [CrossRef]

21. Fontenille, D.; Toto, J.C. Aedes (Stegomyia) albopictus (Skuse), vecteur potentiel du virus de la dengue, a envahi les villes du sud du Cameroun. Bull. Société Pathol. Exot. 2003, 96, 1.

22. Demanou, M.; Pouillot, R.; Grandadam, M.; Boisier, P.; Kamgang, B.; Hervé, J.P.; Rogier, C.; Rousset, D.; Paupy, C. Evidence of dengue virus transmission and factors associated with the presence of anti-dengue virus antibodies in humans in three major towns in Cameroon. PLoS Negl. Trop. Dis. 2014, 8, e2950. [CrossRef]

23. Yousseu, F.B.S.; Nemg, F.B.S.; Ngouanet, S.A.; Mekanda, F.M.O.; Demanou, M. Detection and serotyping of dengue viruses in febrile patients consulting at the New-Bell District Hospital in Douala, Cameroon. PLoS ONE 2018, 13, e0204143. [CrossRef] 
24. Tchuandom, S.B.; Tchadji, J.C.; Tchouangueu, T.F.; Biloa, M.Z.; Atabonkeng, E.P.; Fumba, M.I.M.; Massom, E.S.; Nchinda, G.; Kuiate, J.-R. A Cross-sectional study of acute dengue infection in paediatric clinics in Cameroon. BMC Public Health 2019, 19, 958. [CrossRef]

25. Tchuandom, S.B.; Tchouangueu, T.F.; Antonio-Nkondjio, C.; Lissom, A.; Djang, J.O.N.; Atabonkeng, E.P.; Kechia, A.; Nchinda, G.; Kuiate, J.-R. Seroprevalence of dengue virus among children presenting with febrile illness in some public health facilities in Cameroon. Pan Afr. Med. J. 2018, 31. [CrossRef]

26. Simo, F.B.N.; Yousseu, F.B.S.; Mbarga, A.E.; Bigna, J.J.; Melong, A.; Ntoude, A.; Kamgang, B.; Bouyne, R.; Fewou, P.M.; Demanou, $\mathrm{M}$. Investigation of an outbreak of dengue virus serotype 1 in a rural area of Kribi, South Cameroon: A cross-sectional study. Intervirology 2018, 61, 265-271. [CrossRef]

27. Gake, B.; Vernet, M.A.; Leparc-Goffart, I.; Drexler, J.F.; Gould, E.A.; Gallian, P.; de Lamballerie, X.; Gake, B.; Vernet, M.A.; LeparcGoffart, I.; et al. Low seroprevalence of zika virus in cameroonian blood donors. Braz. J. Infect. Dis. 2017, 21, 481-483. [CrossRef]

28. Abramides, G.C.; Roiz, D.; Guitart, R.; Quintana, S.; Guerrero, I.; Giménez, N. Effectiveness of a multiple intervention strategy for the control of the tiger mosquito (Aedes albopictus) in Spain. Trans. R. Soc. Trop. Med. Hyg. 2011, 105, 281-288. [CrossRef] [PubMed]

29. Fonseca, D.M.; Unlu, I.; Crepeau, T.; Farajollahi, A.; Healy, S.P.; Bartlett-Healy, K.; Strickman, D.; Gaugler, R.; Hamilton, G.; Kline, D.; et al. Area-wide management of Aedes albopictus. Part 2: Gauging the efficacy of traditional integrated pest control measures against urban container mosquitoes. Pest. Manag. Sci. 2013, 69, 1351-1361. [CrossRef] [PubMed]

30. WHO. 2009 Dengue Guidelines for Diagnosis, Traitement, Prevention and Control., TDR for Research on Diseases and Poverty, new ed.; WHO: Geneva, Switzerland, 2009; p. 160.

31. Buhler, C.; Winkler, V.; Runge-Ranzinger, S.; Boyce, R.; Horstick, O. Environmental methods for dengue vector control-A systematic review and meta-analysis. PLoS Negl. Trop. Dis 2019, 13. [CrossRef] [PubMed]

32. Weeratunga, P.; Rodrigo, C.; Fernando, S.D.; Rajapakse, S. Control methods for Aedes albopictus and Aedes aegypti. Cochrane Database Syst. Rev. 2017, 2017. [CrossRef]

33. Roiz, D.; Wilson, A.L.; Scott, T.W.; Fonseca, D.M.; Jourdain, F.; Müller, P.; Velayudhan, R.; Corbel, V. Integrated Aedes management for the control of Aedes-Borne diseases. PLoS Negl. Trop. Dis. 2018, 12, e0006845. [CrossRef]

34. Mahmud, M.; Mutalip, H.; Lodz, N.A.; Muhammad, E.; Yoep, N.; Hasim, H.; Paiwai, F.; Rajarethinam, J.; Aik, J.; Muhammad, N. Environmental management for dengue control: A systematic review protocol. BMJ Open 2019, 9, e026101. [CrossRef]

35. Antonio-Nkondjio, C.; Ndo, C.; Njiokou, F.; Bigoga, J.D.; Awono-Ambene, P.; Etang, J.; Ekobo, A.S.; Wondji, C.S. Review of malaria situation in Cameroon: Technical viewpoint on challenges and prospects for disease elimination. Parasites Vectors 2019, 12, 501. [CrossRef]

36. WHO. Guidelines for Malaria Vector Control; WHO: Geneva, Switzerland, 2019; p. 171.

37. Nchoutpouen, E.; Abdou, T.; Djiappi-Tchamen, B.; Djamouko-Djonkam, L.; Kopya, E.; Ngadjeu, C.; Doumbe, B.; Awono-Ambene, P.; Kekeunou, S.; Wondji, C.; et al. Culex species diversity, susceptibility to insecticides and role as potential vector of lymphatic filariasis in the city of Yaoundé, Cameroon. PLoS Negl. Trop. Dis. 2019, 13. [CrossRef]

38. Kamgang, B.; Yougang, A.P.; Tchoupo, M.; Riveron, J.M.; Wondji, C. Temporal distribution and insecticide resistance profile of two major arbovirus vectors Aedes aegypti and Aedes albopictus in Yaoundé, the capital city of Cameroon. Parasites Vectors 2017, 10, 469. [CrossRef]

39. Ngo, O.; Akono, P.; Ngo, J.; Nko'o, E.; Tonga, C.; Foko, G.; Kekeunou, S. Adaptation compétitive d'Aedes albopictus Skuse, 1894 en présence d'Aedes aegypti Linné, 1862 dans quelques gîtes larvaires temporaires de la ville de Douala (Cameroun) dans un contexte de résistance aux pyréthrinoïdes. Bull. Soc. Pathol. Exot. 2020, 9.

40. Seixas, G.; Grigoraki, L.; Weetman, D.; Vicente, J.L.; Silva, A.C.; Pinto, J.; Vontas, J.; Sousa, C.A. Insecticide resistance is mediated by multiple mechanisms in recently introduced Aedes aegypti from Madeira Island (Portugal). PLoS Negl. Trop. Dis. 2017, 11, e0005799. [CrossRef]

41. Chareonviriyaphap, T.; Bangs, M.J.; Suwonkerd, W.; Kongmee, M.; Corbel, V.; Ngoen-Klan, R. Review of insecticide resistance and behavioral avoidance of vectors of human diseases in Thailand. Parasites Vectors 2013, 6, 280. [CrossRef]

42. Sathantriphop, S.; White, S.A.; Achee, N.L.; Sanguanpong, U. Chareonviriyaphap, eeraphap behavioral responses of Aedes aegypti, Aedes albopictus, Culex quinquefasciatus, and Anopheles minimus against various synthetic and natural repellent compounds. J. Vector Ecol. 2014, 39. [CrossRef]

43. Wood, O.; Hanrahan, S.; Coetzee, M.; Koekemoer, L.; Brooke, B. Cuticle thickening associated with pyrethroid resistance in the major malaria vector Anopheles funestus. Parasites Vectors 2010, 3, 67. [CrossRef]

44. Yahouédo, G.A.; Chandre, F.; Rossignol, M.; Ginibre, C.; Balabanidou, V.; Mendez, N.G.A.; Pigeon, O.; Vontas, J.; Cornelie, S. Contributions of cuticle permeability and enzyme detoxification to pyrethroid resistance in the major malaria vector Anopheles gambiae. Sci. Rep. 2017, 7, 11091. [CrossRef]

45. Balabanidou, V.; Grigoraki, L.; Vontas, J. Insect cuticle: A critical determinant of insecticide resistance. Curr. Opin. Insect Sci. 2018, 27, 68-74. [CrossRef]

46. Simma, E.A.; Dermauw, W.; Balabanidou, V.; Snoeck, S.; Bryon, A.; Clark, R.M.; Yewhalaw, D.; Vontas, J.; Duchateau, L.; Leeuwen, T.V. Genome-wide gene expression profiling reveals that cuticle alterations and P450 detoxification are associated with pyrethroid resistance in Anopheles arabiensis populations from Ethiopia. Pest. Manag. Sci. 2018. [CrossRef]

47. Hemingway, J.; Hawkes, N.; McCarroll, L.; Ranson, H. The molecular basis of insecticide resistance in Mosquitoes. Insect Biochem. Mol. Biol. 2004, 34, 653-665. [CrossRef] 
48. Hemingway, J.; Field, L.; Vontas, J. An overview of insecticide resistance. Science 2002, 298, 96-97. [CrossRef]

49. Ranson, H.; N'guessan, R.; Lines, J.; Moiroux, N.; Nkuni, Z.; Corbel, V. Pyrethroid resistance in African Anopheline Mosquitoes: What are the implications for malaria control? Trends Parasitol. 2011, 27, 91-98. [CrossRef]

50. Brogdon, W.; Mcallister, J. Insecticide resistance and vector control. Emerg. Infect. Dis. 2004, 4, 605-613. [CrossRef]

51. Enayati, A.A.; Ranson, H.; Hemingway, J. Insect glutathione s-transferases and insecticide resistance. Insect Mol. Biol. 2005, 14, 3-8. [CrossRef] [PubMed]

52. Kasai, S.; Komagata, O.; Itokawa, K.; Shono, T.; Ng, L.C.; Kobayashi, M.; Tomita, T. Mechanisms of pyrethroid resistance in the dengue mosquito vector, Aedes aegypti: Target site insensitivity, penetration, and metabolism. PLoS Negl. Trop. Dis. 2014, 8, e2948. [CrossRef] [PubMed]

53. Moyes, C.L.; Vontas, J.; Martins, A.J.; Ng, L.C.; Koou, S.Y.; Dusfour, I.; Raghavendra, K.; Pinto, J.; Corbel, V.; David, J.-P.; et al. Contemporary status of insecticide resistance in the major Aedes vectors of arboviruses infecting humans. PLoS Negl. Trop. Dis. 2017, 11, e0005625. [CrossRef] [PubMed]

54. Smith, L.B.; Sears, C.; Sun, H.; Mertz, R.W.; Kasai, S.; Scott, J.G. CYP-mediated resistance and cross-resistance to pyrethroids and organophosphates in Aedes aegypti in the presence and absence of Kdr. Pestic. Biochem. Physiol. 2019, 160, 119-126. [CrossRef] [PubMed]

55. Vontas, J.; Katsavou, E.; Mavridis, K. Cytochrome P450-based metabolic insecticide resistance in Anopheles and Aedes Mosquito Vectors: Muddying the waters. Pestic. Biochem. Physiol. 2020, 170, 104666. [CrossRef]

56. Ishak, I.H.; Riveron, J.M.; Ibrahim, S.S.; Stott, R.; Longbottom, J.; Irving, H.; Wondji, C.S. the cytochrome P450 gene CYP6P12 confers pyrethroid resistance in Kdr-free Malaysian populations of the Dengue Vector Aedes albopictus. Sci. Rep. 2016, 6, 24707. [CrossRef]

57. Yougang, A.P.; Kamgang, B.; Bahun, T.A.W.; Tedjou, A.N.; Nguiffo-Nguete, D.; Njiokou, F.; Wondji, C.S. First detection of f1534c knockdown resistance mutation in Aedes aegypti (Diptera: Culicidae) from Cameroon. Infect. Dis. Poverty 2020, 9, 152. [CrossRef]

58. Yougang, P.; Kamgang, B.; Armel, T.; Wilson-Bahun, T.; Njiokou, F.; Wondji, C. Nationwide profiling of insecticide resistance in Aedes albopictus (Diptera: Culicidae) in Cameroon. PLoS ONE 2020, 15, e0234572. [CrossRef]

59. Jupp, P. Mosquitoes of Southern Africa; Ekogilde Publishers: Johannesburg, South Africa, 1996; p. 156.

60. WHO. Test Procedures for Insecticide Resistance Monitoring in Malaria Vectors Mosquitoes, 2nd ed; WHO: Geneva, Switzerland, 2016.

61. Mavridis, K.; Wipf, N.; Medves, S.; Erquiaga, I.; Müller, P.; Vontas, J. Rapid multiplex gene expression assays for monitoring metabolic resistance in the Major Malaria Vector Anopheles gambiae. Parasites Vectors 2019, 12, 9. [CrossRef]

62. Kothera, L.; Byrd, B.; Savage, H.M. Duplex real-time PCR assay distinguishes Aedes aegypti from Aedes albopictus (Diptera: Culicidae) using DNA from Sonicated first-instar larvae. J. Med. Entomol. 2017, 54, 1567-1572. [CrossRef]

63. Sene, N.; Mavridis, K.; Ndiaye, E.; Diagne, C.; Gaye, A.; Ngom, E.; Ba, Y.; Diallo, D.; Vontas, J.; Dia, I.; et al. Insecticide resistance status and mechanisms in Aedes aegypti populations from SenegaL. PLoS Negl. Trop. Dis. Accept. 2021. [CrossRef]

64. Pfaffl, M.W. A new mathematical model for relative quantification in real-time RT-PCR. Nucleic. Acids. Res. 2001, 29, e45. [CrossRef]

65. Pfaffl, M.W.; Horgan, G.W.; Dempfle, L. Relative expression software tool (REST@) for group-wise comparison and statistical analysis of relative expression results in real-time PCR. Nucleic Acids Res. 2002, 9, 36. [CrossRef]

66. Kamgang, B.; Vazeille, M.; Yougang, A.P.; Tedjou, A.N.; Wilson-Bahun, T.A.; Mousson, L.; Wondji, C.S.; Failloux, A.-B. Potential of Aedes albopictus and Aedes aegypti (Diptera: Culicidae) to transmit yellow fever virus in urban areas in central Africa. Emerg. Microbes Infect. 2019, 8, 1636-1641. [CrossRef]

67. Kamgang, B.; Vazeille, M.; Tedjou, A.; Yougang, A.P.; Wilson-Bahun, T.A.; Mousson, L.; Wondji, C.S.; Failloux, A.-B. Different Populations of Aedes aegypti and Aedes albopictus (Diptera: Culicidae) from central Africa are susceptible to zika virus infection. PLoS Negl. Trop. Dis. 2020, 14, e0008163. [CrossRef]

68. Wilke, A.B.B.; Vasquez, C.; Carvajal, A.; Medina, J.; Chase, C.; Cardenas, G.; Mutebi, J.-P.; Petrie, W.D.; Beier, J.C. Proliferation of Aedes aegypti in urban environments mediated by the availability of key aquatic habitats. Sci. Rep. 2020, 10, 12925. [CrossRef]

69. Dzib-Florez, S.; Ponce-García, G.; Che-Mendoza, A.; Medina-Barreiro, A.; Gray, L.; González-Olvera, G.; Delfin-Gonzalez, H.; Chan-Espinoza, D.; Vadillo-Sánchez, J.; del Castillo-Centeno, L.; et al. Bio-efficacy of commercially available residual insecticides for the control of Aedes aegypti in Mexico. J. Am. Mosq. Control Assoc. 2020, 36, 16-21. [CrossRef]

70. Gray, L.; Florez, S.D.; Barreiro, A.M.; Vadillo-Sánchez, J.; González-Olvera, G.; Lenhart, A.; Manrique-Saide, P.; Vazquez-Prokopec, G.M. Experimental evaluation of the impact of household aerosolized insecticides on pyrethroid resistant Aedes aegypti. Sci. Rep. 2018, 8, 12535. [CrossRef] [PubMed]

71. Ponlawat, A.; Scott, J.G.; Harrington, L.C. Insecticide susceptibility of Aedes aegypti and Aedes albopictus across Thailand. J. Med. Entomol. 2005, 42, 821-825. [CrossRef]

72. Ouattara, L.P.E.; Sangaré, I.; Namountougou, M.; Hien, A.; Ouari, A.; Soma, D.D.; Kassié, D.; Diabaté, A.; Gnankiné, O.; Bonnet, E.; et al. Surveys of arboviruses vectors in four cities stretching along a railway transect of burkina faso: Risk transmission and insecticide susceptibility status of potential vectors. Front. Vet. Sci. 2019, 6. [CrossRef]

73. Marcombe, S.; Fustec, B.; Cattel, J.; Chonephetsarath, S.; Thammavong, P.; Phommavanh, N.; David, J.-P.; Corbel, V.; Sutherland, I.W.; Hertz, J.C.; et al. Distribution of Insecticide Resistance and Mechanisms Involved in the Arbovirus vector Aedes aegypti in laos and implication for vector control. PLoS Negl. Trop. Dis. 2019, 13, e0007852. [CrossRef] 
74. Yap, A.; Chee Dhang, C.; Azirun, M.; Van Lun, L.L. Pyrethroid resistance in the dengue vector Aedes aegypti in Southeast Asia: Present situation and prospects for management. Parasites Vectors 2018, 11. [CrossRef]

75. WHO. Monitoring and Managing Insecticide Resistance in Aedes Mosquito Populations Interim Guidance for Entomologists; WHO: Geneva, Switzerland, 2016.

76. Haddi, K.; Tomé, H.V.V.; Du, Y.; Valbon, W.R.; Nomura, Y.; Martins, G.F.; Dong, K.; Oliveira, E.E. Detection of a new pyrethroid resistance mutation (V410L) in the sodium channel of Aedes aegypti: A potential challenge for mosquito control. Sci. Rep. 2017, 7, 1-9. [CrossRef] [PubMed]

77. Badolo, A.; Sombié, A.; Pignatelli, P.M.; Sanon, A.; Yaméogo, F.; Wangrawa, D.W.; Sanon, A.; Kanuka, H.; McCall, P.J.; Weetman, D. Insecticide resistance levels and mechanisms in Aedes aegypti populations in and around Ouagadougou, Burkina Faso. PLoS Negl. Trop. Dis. 2019, 13, e0007439. [CrossRef] [PubMed]

78. Sombié, A.; Saiki, E.; Yaméogo, F.; Sakurai, T.; Shirozu, T.; Fukumoto, S.; Sanon, A.; Weetman, D.; McCall, P.J.; Kanuka, H.; et al. High frequencies of F1534C and V1016I Kdr mutations and association with pyrethroid resistance in Aedes aegypti from Somgandé (Ouagadougou), Burkina Faso. Trop. Med. Health 2019, 47, 2. [CrossRef] [PubMed]

79. Kudom, A.A. Entomological surveillance to assess potential outbreak of aedes-borne arboviruses and insecticide resistance status of Aedes aegypti from Cape Coast, Ghana. Acta. Tropica. 2020, 202, 105257. [CrossRef] [PubMed]

80. Kawada, H.; Higa, Y.; Futami, K.; Muranami, Y.; Kawashima, E.; Osei, J.H.N.; Sakyi, K.Y.; Dadzie, S.; de Souza, D.K.; Appawu, M.; et al. Discovery of point mutations in the voltage-gated sodium channel from African Aedes aegypti populations: Potential phylogenetic reasons for gene introgression. PLoS Negl. Trop. Dis. 2016, 10, e0004780. [CrossRef]

81. Kushwah, R.B.S.; Dykes, C.L.; Kapoor, N.; Adak, T.; Singh, O.P. Pyrethroid-resistance and presence of two knockdown resistance (Kdr) mutations, F1534C and a novel mutation T1520I, in Indian Aedes aegypti. PLoS Negl. Trop. Dis. 2015, 9, e3332. [CrossRef]

82. Hirata, K.; Komagata, O.; Itokawa, K.; Yamamoto, A.; Tomita, T.; Kasai, S. A single crossing-over event in voltage-sensitive $\mathrm{Na}+$ channel genes may cause critical failure of dengue mosquito control by insecticides. PLoS Negl. Trop. Dis. 2014, 8, e3085. [CrossRef]

83. Li, C.-X.; Kaufman, P.E.; Xue, R.-D.; Zhao, M.-H.; Wang, G.; Yan, T.; Guo, X.-X.; Zhang, Y.-M.; Dong, Y.-D.; Xing, D.; et al. Relationship between insecticide resistance and $\mathrm{Kdr}$ mutations in the dengue vector Aedes aegypti in Southern China. Parasites Vectors 2015, 8, 325. [CrossRef]

84. Kamgang, B.; Wilson-Bahun, T.A.; Yougang, A.P.; Lenga, A.; Wondji, C.S. Contrasting resistance patterns to Type I and II pyrethroids in two major arbovirus vectors Aedes aegypti and Aedes albopictus in the Republic of the Congo, Central Africa. Infect. Dis. Poverty 2020, 9, 23. [CrossRef]

85. Ngoagouni, C.; Kamgang, B.; Brengues, C.; Yahouedo, G.; Paupy, C.; Nakouné, E.; Kazanji, M.; Chandre, F. Susceptibility profile and metabolic mechanisms involved in Aedes aegypti and Aedes albopictus resistant to DDT and deltamethrin in the Central African Republic. Parasites Vectors 2016, 9, 599. [CrossRef]

86. Chen, H.; Li, K.; Wang, X.; Yang, X.; Lin, Y.; Cai, F.; Zhong, W.; Lin, C.; Lin, Z.; Ma, Y. First identification of Kdr allele F1534S in VGSC gene and its association with resistance to pyrethroid insecticides in Aedes albopictus Populations from Haikou City, Hainan Island, China. Infect. Dis. Poverty 2016, 5, 31. [CrossRef]

87. Xu, J.; Bonizzoni, M.; Zhong, D.; Zhou, G.; Cai, S.; Li, Y.; Wang, X.; Lo, E.; Lee, R.; Sheen, R.; et al. Multi-country survey revealed prevalent and novel F1534S mutation in Voltage-Gated Sodium Channel (VGSC) gene in Aedes albopictus. PLoS Negl. Trop. Dis. 2016, 10, e0004696. [CrossRef]

88. Vera-Maloof, F.Z.; Saavedra-Rodriguez, K.; Elizondo-Quiroga, A.E.; Lozano-Fuentes, S.; Iv, W.C.B. Coevolution of the Ile1,016 and Cys1,534 mutations in the voltage gated sodium channel gene of Aedes aegypti in Mexico. PLoS Negl. Trop. Dis. 2015, 9, e0004263. [CrossRef]

89. Stevenson, B.J.; Pignatelli, P.; Nikou, D.; Paine, M.J.I. Pinpointing p450s associated with pyrethroid metabolism in the dengue vector, Aedes aegypti: Developing new tools to combat insecticide resistance. PLoS Negl. Trop. Dis. 2012, 6, e1595. [CrossRef]

90. Pavlidi, N.; Monastirioti, M.; Daborn, P.; Livadaras, I.; Van Leeuwen, T.; Vontas, J. Transgenic expression of the Aedes aegypti CYP9J28 confers pyrethroid resistance in Drosophila Melanogaster. Pestic. Biochem. Physiol. 2012, 104, 132-135. [CrossRef] 